\title{
Narrativas filmoliterarias en Fresa y chocolate. Un caso de estudio en la coproducción durante el período especial cubano
}

\author{
David García-Reyes ${ }^{1}$
}

Recibido: 25 de junio de 2018 / Aceptado: 6 de septiembre de 2018

Resumen. Fresa y chocolate (1993) se convirtió en un fenómeno en el contexto transnacional del cine por su distribución mundial y la representación de algunas realidades cubanas silenciadas y perseguidas. El cuento y el guión de Senel Paz, con la dirección de Tomás Gutiérrez Alea y Juan Carlos Tabío, sirven para diseccionar la vida de los habitantes de la isla. El estudio aborda el proceso creativo del film y muestra diversas lecturas sobre la sociedad, la cultura y la vida privada en Cuba.

Palabras clave: cine cubano; coproducción; homosexualidad; período especial; Senel Paz; Tomás Gutiérrez Alea

\section{[en] Film-Literature Narratives in Strawberry and Chocolate. A Case Study in Co-Production during the Cuban Special Period}

\begin{abstract}
The film Strawberry and Chocolate (Fresa y chocolate, 1993) can be considered a transnational phenomenon in the context of world cinema, regarding its distribution on screens around the world and the representation of persecuted and silenced situations in Cuba. The original story and script by Senel Paz, directed by Tomás Gutiérrez Alea and Juan Carlos Tabío, shows and dissects the inhabitants' life. This study analyzes the creative process related with the translation of the novel into film, showing different readings of society, culture and private life in Cuba.

Keywords: cuban cinema; co-production film; homosexuality; Special Period; Senel Paz; Tomás Gutiérrez Alea

Sumario: 1. Notas introductorias. 2. Etimologías y otras cosmogonías filmoliterarias. 3. Érase una vez...en un bosque, un hombre nuevo que encuentra a un lobo. 4. Aprendiendo del lobo 5. Conductas perseguidas, prácticas proscritas: homosexualidad y sincretismo yoruba. 6. Los restos del naufragio: cuando uno sale de Cuba. 7. Bibliografía.
\end{abstract}

Cómo citar: García-Reyes, D. (2018) Narrativas filmoliterarias en Fresa y Chocolate. Un caso de estudio en la coproducción durante el periodo especial cubano, en Área Abierta. Revista de comunicación audiovisual y publicitaria 19 (1), 75-92. http://dx.doi.org/10.5209/ARAB.60738

1 Universidad de Concepción (Chile)-CONICYT-PFCHA/Doctorado Nacional/ 2017-21171064.
E-mail: mangarcia@udec.cl 
Tierra firme llamaban los antiguos a todo lo que no fuera isla. La isla es, pues, lo menos firme, lo menos tierra de la Tierra

Dulce María Loynaz

\section{Notas introductorias}

El cuento o nouvelle "El lobo, el bosque y el hombre nuevo"2 (1990) de Senel Paz (1950) es el texto matricial de la película Fresa y chocolate (1993), dirigida por Juan Carlos Tabío (1943) y Tomás Gutiérrez Alea (1928-1996). El director Tomás "Titón" Gutiérrez Alea, una de las principales figuras del cine de la más grande de las Antillas, destaca por sus adaptaciones literarias en el contexto cubano. Previamente, antes de colaborar con Paz en la redacción del guion cinematográfico de Fresa y chocolate, había desarrollado el grueso de su carrera tomando como punto de partida obras literarias. Junto a su amigo Néstor Almendros, adaptan un cuento de Franz Kafka en el cortometraje Una confusión cotidiana (1950). Posteriormente, Titón lleva a cabo largometrajes como Las doce sillas (1962), basado en la novela homónima soviética (1928) de Ilf y Petrov; Cumbite (1964), adaptando la novela Gouverneurs de la roséees (1944) del escritor haitiano Jacques Roumain; Memorias del subdesarrollo (1968), adaptando la novela del mismo título (1965) de Edmundo Desnoes; hasta llegar a La última cena (1976), partiendo de El ingenio (1964) de Manuel Moreno Fraginals o Cartas del Parque (1988), tomando un argumento original de Gabriel García Márquez.

La génesis de Fresa y chocolate, viene precedida por el contexto industrial del cine cubano desde 1959, marcado por las dificultades en la producción y el auspicio del Instituto Cubano de Arte e Industria Cinematográficos (ICAIC). El ICAIC, fundado poco después del triunfo de la revolución y dirigido durante la mayor parte de su existencia por Alfredo Guevara (1925-2013), tuvo a Gutiérrez Alea como uno de sus principales colaboradores. Tras la caída del muro de Berlín (1989) y el colapso de la Unión Soviética (1991), la isla va a sufrir una difícil situación, acompañada de una carestía de productos básicos y de una miseria como nunca antes había vivido la población cubana, circunstancias que se verían agravadas por el bloqueo económico estadounidense. El comienzo del periodo especial en tiempos de paz (1991-1995) coincide con el regreso de Guevara al ICAIC tras su estadía como embajador de Cuba (1983-1991) en la UNESCO, donde impulsa importantes alianzas para estimular la producción nacional a través de la coproducción.

Con anterioridad, la producción audiovisual cubana se había visto alentada por la colaboración con otras industrias iberoamericanas. En el medio cubano, la coproducción es una forma de supervivencia en el marco de los distintos acuerdos internacionales en materia de cooperación, favoreciendo un cine transnacional. Fresa y chocolate es un epitome de esta cooperación, con capitales españoles y mexicanos. Este escenario hubiera resultado improbable sin la decidida apuesta y el impulso cultural promovido por los gobiernos socialistas de España (1982-1996), cimentado en la Ley de protección del cine español (1983), marco que promovió de forma decidida la producción nacional y la coproducción con Iberoamérica. La película de Gutiérrez Alea y Tabío se beneficia de esta disposición, siendo coproducida por el ICAIC,

2 A partir de este punto al citar el título del cuento se abreviará con "El lobo". 
la cadena pública española Telemadrid, la Sociedad General de Autores y Editores (SGAE), el Instituto Mexicano de Cinematografía (IMCINE) y la compañía azteca Tabasco Films. El propio Senel Paz realiza un certero análisis de la realidad del cine cubano de los últimos veinte años y su posición como cine resistente y casi disidente; Paz considera que el cine realizado en la isla, al contrario de la opinión favorable del público cubano, no es muy del gusto de las autoridades revolucionarias (Simis, 2015).

La situación de Cuba en el momento de la producción del film era muy compleja, con la dependencia económica, política y tecnológica de la Unión Soviética, tal y como reflejan los aportes en esta materia del historiador Oscar Zanetti (2013). A partir de 1991, las condiciones para la subsistencia presentan un escenario dramático desde el punto de vista de la alimentación y el abastecimiento de otros suministros básicos para sus habitantes. El contexto de producción del filme, en plena vorágine del período especial, imbuido de una carestía y urgencia social extremas, contrasta con el cuento que adapta. "El lobo" está ambientado en los años ochenta, cuando aún no se había producido el colapso soviético que desencadenó la situación sobrevenida a principios de la década de 1990. Gutiérrez Alea y Tabío optan por ambientar el tiempo fílmico en una época casi tan difusa como la de la nouvelle. Algunos estudios sitúan erróneamente la ambientación de Fresa y chocolate durante los años noventa del período especial (Nascimento, 2015: 39). Sin embargo, la única referencia al contexto se alude de forma pasajera cuando al llegar David, el protagonista, a la residencia universitaria donde vive: Miguel, su compañero de militancia está viendo las imágenes de un noticiario informativo sobre la derrota del dictador nicaragüense Anastasio Somoza (1979) y su huida a Estados Unidos durante la revolución sandinista. Gutiérrez Alea sitúa la acción y confirma la cronología en una entrevista durante la promoción internacional del filme (West, 1995). Este punto resulta bastante problemático para que el espectador sea consciente de la ambientación histórica. Los directores y el guionista quisieron marcar el punto álgido de la persecución a los homosexuales en la isla, anterior al multitudinario éxodo del Puerto de Mariel (15/04/1980-31/10/1980), como si la situación desde 1980 hubiese cambiado tan radicalmente que la exclusión y la represión desapareciesen en Cuba a partir de 1981.

Bénédicte Brémard (2017) señala que Gutiérrez Alea se sirve de la adaptación de la nouvelle de Senel Paz para mitigar su propia conciencia por el que fuera su amigo, el director de fotografía Néstor Almendros, fallecido en 1992, poco antes del rodaje del film. Titón acusó de simplista el documental Conducta impropia (Mauvaise conduite, 1984) que el cineasta hispanocubano codirigió junto a Orlando Jiménez Leal', donde se denuncian la persecución y las purgas morales a las que fueron sometidos los homosexuales cubanos desde el comienzo de la revolución hasta principios de la década de 1980. Describe a las Unidades Militares de Ayuda a la Producción (UMAP), como duros campos de reclusión y trabajo que sirvieron, entre 1965 y 1968, para aislar, "reeducar" y "hacer hombres de provecho" para la revolución, a jóvenes en edad militar, principalmente personas homosexuales y de distintas confesiones religiosas que eran contrarias a realizar el servicio militar o que eran considerados no aptos para el mismo.

\footnotetext{
Fresa y chocolate llegó tarde, se estrenó en EE.UU. tres años después que Almendros muriese. El final de la amistad entre ambos cineastas y la agría polémica arranca a causa del estreno del documental de Jiménez y Almendros, una disputa con Titón, prensa escrita mediante, que sucede entre agosto y octubre de 1984 (Gutiérrez Alea, 1984).
} 


\section{Etimologías y otras cosmogonías filmoliterarias}

En el texto literario, la alusión normativa y prejuiciosa a los sabores (Paz, 1994: 5) configura el título del filme: los gustos característicos de lo femenino, en el caso de la fresa, y del chocolate, de lo masculino. Desde parámetros de roles, dentro de la acción dramática, el título identifica a la fresa con la homosexualidad y al chocolate con lo heterosexual. Si el análisis se realiza desde un posicionamiento etnográfico, la fresa podría aludir a lo caucásico, categoría en la que se encontraría el personaje de Diego (Jorge Perugorría), y el chocolate a la tez más morena de David (Vladimir Cruz). El componente racial es, si cabe, más explícito en el filme. Un debate secular entre los protagonistas se escenifica en el primer encuentro en "La Guarida" de Diego en relación a los negros cubanos, asociándolos al griterío, al hurto o al vigor sexual (Paz, 1994: 19), reducciones racistas ${ }^{4}$ todas ellas que, en boca de un personaje homosexual, no dejan de resultar insólitas. El diálogo resulta sintomático de una realidad perenne en la formulación de la identidad nacional cubana (Naranjo y García González, 2000), que aparece soslayada tanto en "El lobo" como en Fresa y chocolate. Por mucho que, desde la revolución, la consideración de las comunidades negra y mulata haya mejorado institucionalmente, los afrocubanos han seguido estando relegados socialmente.

Partiendo del estudio de Carlos Paz (1997), la etimología nominal de los personajes en el cuento y en el film, vendría a sugerir que David tendría resonancias bíblicas en su enfrentamiento con Diego. Aunque esta distribución de roles produciría una inversión de papeles, porque el joven estudiante, en sus parlamentos cinematográficos, resulta tan prepotente y tiránico como Goliat, si bien con una agresividad ante lo desconocido que va atenuándose. Destilando ironía, en el cuento, David se define como un narrador lleno de inseguridades, dudando de su propia identidad, y presenta características que le definen como comunista, heterosexual y ateo, además de percepciones homófobas adquiridas durante su formación social e ideológica, prejuicios de los que el protagonista es consciente en el relato de Paz (Jablonska, 2005: 124-125) y rasgos que se exacerban en el filme. A medida que la trama avanza, el personaje de Diego rebaja sus instintos para constituirse en una síntesis del marginal, del perseguido y del cubano patriota e incomprendido, una situación que le despoja de parte de su identidad sexual y que tan vehementemente parecía defender. Esa situación deviene mediación para convertirse en faro y maestro de David, al que introduce en lecturas y nociones culturales no muy apreciadas por la revolución. Además, Diego le empuja a la carnalidad pujante y desaforada de Nancy, convertida al igual que la comida almuerzo lezamiano-, las lecturas - de Mario Vargas Llosa a John Donne-u otras cuestiones antropológicas y culturales, en instrumento de un Pigmalión que esculpe al "hombre nuevo" desde la tolerancia, el respeto a la diferencia y el conocimiento de la diversidad.

La posición de Diego como referente y antagonista de la cultura revolucionaria es paradigmática, pues, aunque no se destaca como un opositor activo de lo revolucionario, sí muestra una disidencia frente a la oficialidad. Los libros "contrarrevolucio-

$4 \quad$ Las investigadoras Aline Helg (1994) y Consuelo Naranjo (2007) han reflejado en sus investigaciones algunas de las implicaciones generadas en torno a lo negro vinculadas con el retraso, el primitivismo y lo atávico, legitimación de un discurso racista blanco que se ha impuesto en todas las esferas de la sociedad cubana. 
narios" Campos de Nijar (1959) de Juan Goytisolo y Conversaciones en la Catedral (1969) de Vargas Llosa ${ }^{6}$ son los anzuelos con los que Diego intenta atraer al escritor en ciernes que hay en David, paradójicamente sometido a la vergüenza que le genera haber participado en un montaje teatral de Casa de muñecas de Henrik Ibsen — crítica feroz a las convenciones sociales decimonónicas - y otro de los elementos extorsivos con los que el lobo agitador que es Diego intenta atraerle hasta "La Guarida" . La localización ${ }^{8}$ de la vivienda se ubica en el número 418 de calle Concordia, entre Gervasio y Escobar, en Centro Habana, circunscripción perteneciente a la provincia de La Habana y ubicado al norte de La Habana Vieja. Fresa y chocolate comparte el mismo topos que la obra literaria del escritor cubano Pedro Juan Gutiérrez (1950), pero se aleja de la crudeza de la precariedad que inspira su prosa (García-Reyes y Ruiz García, 2017: 216).

Como señala Pascale Thibaudeau (2012), el relato evoca en su título los cuentos clásicos, el lobo y el bosque. El lobo sería Diego, escondido en su "Guarida", localizada en el bosque, alegoría de Cuba. La referencia al hombre nuevo remite a la conceptualización acuñada por Ernesto Guevara en su texto El socialismo y el hombre nuevo (1965). David sería, en parte, ese prototipo de hombre nuevo al que aspira la revolución, aunque su verdadera transformación es la adquisición de respeto y tolerancia por la diferencia e interés por la diversidad cultural. En cuanto al nombre de la nouvelle, se puede trazar un sustrato precedente en la referencialidad con el primer cortometraje rodado en $8 \mathrm{~mm}$ en 1947 por Gutiérrez Alea, La caperucita roja, donde se aborda la cita al clásico cuento versionado por Charles Perrault y los hermanos Grimm. El hombre nuevo, el ingenuo David, sería una suerte de Caperucita que se adentra en "La Guarida" de Diego, el lobo. Un lobo que considera "una burla, propaganda socialista" el concepto del hombre nuevo (Paz, 1994: 14).

En obras precedentes, Senel Paz ya había incorporado la inquietud por los personajes que se entrecruzan en su repertorio. En las colaboraciones cinematográficas anteriores del escritor y guionista, los guiones de Una novia para David (1985) de Orlando Rojas y Adorables mentiras (1992) de Gerardo Chijona, se presentan, cinematográficamente hablando, los personajes de Miguel y Nancy que luego aparecerán en Fresa y chocolate (Restom, 2003: 96). Los personajes en el filme vuelven a ser interpretados por el actor Francisco Gattorno y la actriz Mirtha Ibarra. No sólo Miguel o Nancy se encuentran en el universo creativo de Paz. El personaje de Nancy

5 En el film y en el cuento, el escritor Juan Goytisolo aparece como una referencia para Diego. A la condición homosexual de Goytisolo se suma su evolución ideológica, desde el entusiasmo inicial al desencanto generado por la revolución. Antes de concluir la primera década de la Revolución cubana, desde posicionamientos próximos a la izquierda, Jorge Semprún, Vargas Llosa y el propio Goytisolo se convierten en críticos con las políticas represivas cubanas contra intelectuales como Heberto Padilla (1971) y - en el caso particular del escritor español- a la persecución castrista de los homosexuales (Domínguez Búrdalo, 2006).

6 Desde las primeras páginas y secuencias, se aprecia la profusión de citas literarias. En la nouvelle, aludiendo a la Biblioteca Breve de la editorial Seix Barral (Paz, 1994: 6) aunque mencionando otra novela: La guerra del fin del mundo (1981). La fecha de publicación de la misma clarifica la ambientación de "El lobo" a mediados o finales de los ochenta, que es la gran novela de Vargas Llosa de este período. Antes de la aparición del cuento de Senel Paz, el escritor peruano publicó cuatro novelas: Historia de Mayta (1984), ¿Quién mató a Palomino Molero? (1986), El hablador (1987) y Elogio de la madrastra (1988).

7 En el cuento y en el filme, denominación que recibe el apartamento de Diego, principal espacio de la acción dramática, donde suceden más de la mitad de las secuencias.

8 En la actualidad, bajo el nombre de "La Guarida" existe un restaurante que busca atraer al turismo internacional con el reclamo de ser el inmueble donde se rodó la película, dispone de elementos originales o similares del atrezzo como el frigorífico azul al que Diego conoce como Roco, electrodoméstico de la marca Frigidaire del año 1952. http://www.laguarida.com/ 
contrasta con las tipologías femeninas en la nouvelle, que aparecen de forma muy velada y es uno de los grandes aciertos. El personaje de Nancy es voluble, intenso y ciclotímico, además presenta una inestabilidad emocional que le empuja a autolesionarse frecuentemente sin llegar nunca a consumar el suicidio.

En Fresa y chocolate se introduce de forma gráfica algo mencionado fugazmente en el texto literario: la ruptura de David con su novia. Vivian, exnovia de David, es un personaje de gran importancia en el devenir dramático del film, citado sólo dos veces en la trama de "El lobo" (Paz, 1994: 5-6) aparece en el cuento "No le digas que la quieres", rasgo que empareja a Paz con creadores latinoamericanos como Gabriel García Márquez y configura una cosmogonía y un imaginario particular dentro de la obra literaria del escritor, prefiguraciones tipológicas de lo que el espectador encuentra en Fresa y chocolate disponen un patrón seriado que se repite dentro de la obra de Paz (Seguin: 2011). Vivian asume un matrimonio interesado hacia un funcionario diplomático frente a la vida que le puede ofrecer David, algo que la sitúa en una escala moralmente inferior a la del protagonista; Vivian privilegia su estatus y cuestiones materiales respecto al amor que comparte con David.

\section{3. Érase una vez... en un bosque, un hombre nuevo que encuentra a un lobo}

La presentación de David Álvarez, estudiante de ciencias políticas e idealista militante de la Unión de Jóvenes Comunistas cubanos, lleva al espectador a una oscura habitación en una posada donde pretende mantener relaciones con Vivian, su novia. La situación presenta a los jóvenes como neófitos sexuales y la iniciativa, que parece llevar a cabo David, no se consuma ante las reticencias de Vivian, por lo que él promete que no tendrán relaciones hasta casarse. Tras los créditos, David ve como la que fuera su novia contrae matrimonio con un funcionario en una zona residencial de La Habana. A lo largo del film se aprecia que los intereses reales de Vivian eran materiales. Como apunta Seguin (2011: 328), a partir del texto matricial, el film se organiza e incluye casi completamente la larga analepsis con la que se ordena el cuento. La diferencia fundamental es que, al cambiar el soporte narrativo, el lector atesora información sobre la relación entre David y Diego, pues desde los primeros párrafos del cuento, se atisba la amistad entre ambos. En el relato cinematográfico la tensión dramática está intensificada y el espectador de forma lineal es testigo de dicha relación.

A partir del rechazo de Vivian, David conoce a Diego en la heladería Coppelia ${ }^{9}$, la primera referencia intertextual del film, que es conocida como la catedral del helado (Paz, 1994: 5). La ocupación de Diego, que dice ser fotógrafo en la heladería, se intuye relacionada con cuestiones de gestión y promoción cultural. Diego ha observado a David y pretende ganar una apuesta con su amigo Germán, que no es otra que la de seducir al estudiante. El método empleado para atraerle es mostrarle algunos ejemplares de libros con la intención de que acepte la invitación a su casa. A partir de ese momento y a pesar de no conseguir sus objetivos sexuales, Diego establece una relación con David que evoluciona en un proceso de conocimiento y aceptación de

Cadena estatal de heladerías, la sucursal habanera es un enorme edificio donde acuden miles de personas a diario (Lam, 2016). El nombre hace referencia directa a Coppélia (1870), ballet compuesto por Léo Delibes. La alusión al mundo del Ballet en el cuento viene signada en la cita a la figura de la bailarina y coreógrafa cubana Alicia Alonso y referencias a ballets como Giselle o El lago de los cisnes. Además, Diego considera la danza una manifestación artística preminente, "en cuanto al ballet, que era su fuerte, no me perdía una función" (Paz, 1994: 20). En el filme, en cambio, se omiten dichas citas a al mundo del ballet. 
Diego por parte de David, tanto en el relato como en el film, la desconfianza hacia el "contrarrevolucionario" homosexual alimenta la reflexión en relación a la masculinidad (Nascimento, 2015: 39-40), despojándose David de prejuicios atávicos y de una homofobia plagada de ignorancia. Cuento y film concluyen mostrando un afecto sincero y una comprensión de la diversidad que va más allá de percepciones reductivas.

\section{Aprendiendo del lobo}

En la pared de la sala de "La Guarida" se encuentra dispuesto un altar a la cubanía (Imagen 1), lleno de libros, cuadros, fotos y objetos singulares. La escenografía presenta el muro como una suerte de horror vacui, que configura muchos matices del personaje de Diego. En cambio, en el cuento, el apartamento se encuentra desnudo de aditivos, siendo descrito como un lugar pulcro y neutro (Paz, 1994: 11). David provoca la burla de Diego, pues el primero cree que José Lezama Lima ${ }^{10}$ es el padre de Diego al ver una fotografía del escritor colgada en el altar cubano (Imagen 2). En este escenario, Diego se va a convertir en mentor de David. La seducción erótica se transforma en seducción intelectual. David asume consciente su rol pasivo, dejándose aconsejar y guiar en lecturas, inquietudes culturales y opciones de vida. El joven estudiante se va desprendiendo de sus condicionantes y descartando la idea de denunciar a Diego, quien es presentado como un personaje de gran cultura, crítico con los dogmas revolucionarios y que en el ámbito privado vive su condición homosexual.
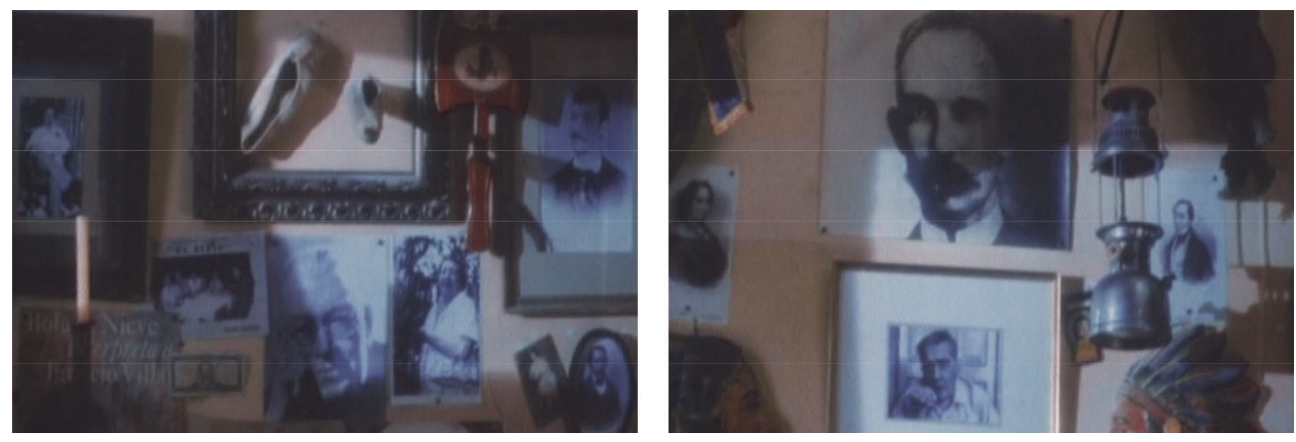

Imágenes 1 y 2. El altar a la cubanía en "La Guarida" de Diego. [Fuente: fotogramas de Fresa y chocolate, Fnac-Avalon (2010)]

Para entender el proceso de inmersión cultural que Diego aplica en David, resulta práctico visualizar cómo se disponen referencias intertextuales que incluyen la mención de escritores cubanos, iberoamericanos o anglosajones. La construcción de este verdadero mosaico de citas, que remite de forma profusa a la formulación intertextual bajtiniana, permite situar sintética y sucintamente esta referencialidad en una tabla de citas sincrónicas en el cuento y en el filme, junto a otras que sólo aparecen en uno de los textos (Tabla 1).

10 Habiendo fallecido Lezama Lima en 1976 y estando ambientado el film a finales de los setenta, denota la ignorancia de David Álvarez y el olvido a la ilustre y oronda figura de la isla, que vivió la decadencia habanera desde la ventana de su casa en el número 162 de la céntrica calle Trocadero. 
Tabla 1. Referencias intertextuales: convergencias y divergencias referenciales entre el cuento "El lobo" y la película Fresa y chocolate. [Fuente: elaboración propia]

\begin{tabular}{|c|c|c|c|}
\hline & $\begin{array}{l}\text { El lobo, el bosque } \\
\text { y el hombre nuevo }\end{array}$ & Fresa y Chocolate & $\begin{array}{l}\text { Referencias comunes } \\
\text { en el cuento y el film }\end{array}$ \\
\hline $\begin{array}{l}\text { Referencias } \\
\text { a libros, } \\
\text { publicaciones } \\
\text { periódicas y } \\
\text { composiciones } \\
\text { musicales }\end{array}$ & $\begin{array}{l}\text {-La guerra del fin del } \\
\text { mundo (1981) de Mario } \\
\text { Vargas Llosa } \\
\text {-Tres tristes tigres (1965) } \\
\text { de Guillermo Cabrera } \\
\text { Infante (1929-2005) } \\
\text {-El lago de los cisnes } \\
\text { (1877) } \\
\text {-Origenes (1944-1956), } \\
\text { revista cultural fundada } \\
\text { por José Rodríguez Feo } \\
\text { (1920-1933) y Lezama } \\
\text { Lima } \\
\text {-Verde Olivo (1959-), } \\
\text { revista de las Fuerzas } \\
\text { Armadas Revolucionarias } \\
\text { cubanas }\end{array}$ & $\begin{array}{l}\text {-Campos de Níjar (1959) } \\
\text { de Juan Goytisolo } \\
\text {-Conversaciones en la } \\
\text { Catedral (1969) de Mario } \\
\text { Vargas Llosa } \\
\text { - "Fefita", tema musical } \\
\text { de José Urfé (1879-1957), } \\
\text { compositor cubano } \\
\text { - "A Bayamo en coche", } \\
\text { tema de Adalberto Alvarez } \\
\text { (1948), compositor y } \\
\text { pianista cubano } \\
\text { - "Tú me sabes } \\
\text { comprender", tema } \\
\text { musical de Ricardo Pérez } \\
\text { (1924-2010) e interpretado } \\
\text { por Benny Moré (1919- } \\
\text { 1963) } \\
\text { - "Ya ves" (1978), canción } \\
\text { de Pablo Milanés (1943), } \\
\text { cantautor cubano }\end{array}$ & $\begin{array}{l}\text {-Casa de muñecas } \\
(1879) \text {, obra de teatro } \\
\text { de Henrik Ibsen (1828- } \\
\text { 1906) } \\
\text {-Paradiso (1966) de } \\
\text { José Lezama Lima } \\
\text {-Giselle (1841) }\end{array}$ \\
\hline $\begin{array}{l}\text { Referencias a } \\
\text { autores }\end{array}$ & $\begin{array}{l}\text {-Condesa de Merlín, } \\
\text { seudónimo de María de las } \\
\text { Mercedes Beltrán Santa } \\
\text { Cruz } \\
\text { (1789-1852), escritora } \\
\text { hispanocubana } \\
\text {-Juana Borrero (1877- } \\
\text { 1897), poeta cubana } \\
\text {-Carlos Loveira y Chirino } \\
\text { (1882-1928), novelista } \\
\text { naturalista cubano } \\
\text {-Dulce María Borrero } \\
\text { (1883-1945), poeta y } \\
\text { pedagoga cubana } \\
\text {-Juana de Ibarbourou } \\
\text { (1892-1979), escritora y } \\
\text { poeta uruguaya } \\
\text {-Alejo Carpentier (1904- } \\
\text { 1980), escritor cubano } \\
\text {-Flor Loynaz (1908-1985), } \\
\text { poeta cubana } \\
\text {-Mirta Aguirre (1912- } \\
\text { 1980), escritora y poeta } \\
\text { cubana }\end{array}$ & $\begin{array}{l}\text {-Fiódor Dostoyevski } \\
\text { (1821-1881), escritor ruso } \\
\text {-Oscar Wilde (1854-1900), } \\
\text { escritor británico } \\
\text {-Ernest Hemingway } \\
\text { (1899-1961), escritor } \\
\text { estadounidense } \\
\text {-Truman Capote (1924- } \\
\text { 1984), periodista y escritor } \\
\text { estadounidense }\end{array}$ & $\begin{array}{l}\text {-John Donne (1572- } \\
\text { 1631), poeta inglés } \\
\text {-Juan Clemente Zenea } \\
\text { (1838-1871), escritor } \\
\text { cubano } \\
\text {-Constantin Kavafis } \\
\text { (1863-1933), poeta } \\
\text { egipcio en lengua } \\
\text { griega } \\
\text {-José Martí (1853- } \\
\text { 1895), escritor y } \\
\text { héroe cubano de la } \\
\text { Independencia } \\
\text {-Federico García Lorca } \\
\text { (1898-1936), poeta y } \\
\text { escritor español } \\
\text {-José Lezama Lima } \\
\text { (1910-1976) } \\
\text {-Dulce María Loynaz } \\
\text { (1902-1997), poeta y } \\
\text { escritora cubana } \\
\text {-Juan Goytisolo (1931- } \\
\text { 2017), escritor español } \\
\text {-Mario Vargas Llosa } \\
\text { (1936), escritor } \\
\text { peruano }\end{array}$ \\
\hline
\end{tabular}




\begin{tabular}{|c|c|c|c|}
\hline & $\begin{array}{l}\text { El lobo, el bosque } \\
\text { y el hombre nuevo }\end{array}$ & Fresa y Chocolate & $\begin{array}{l}\text { Referencias comunes } \\
\text { en el cuento y el film }\end{array}$ \\
\hline $\begin{array}{l}\text { Referencias } \\
\text { a ensayos de } \\
\text { antropología, } \\
\text { etnología } \\
\text { o lenguaje } \\
\text { cubanos }\end{array}$ & $\begin{array}{l}\text {-Azúcar y población en las } \\
\text { Antillas (1927) } \\
\text {-Indagación del choteo } \\
\text { (1928) } \\
\text {-Americanismos y } \\
\text { cubanismos literarios } \\
\text { (1932) } \\
\text { - Contrapunteo cubano del } \\
\text { tabaco y el azúcar (1940) } \\
\text { - El monte (1954) }\end{array}$ & & \\
\hline $\begin{array}{l}\text { Referencias a } \\
\text { intérpretes y } \\
\text { compositores } \\
\text { musicales }\end{array}$ & $\begin{array}{l}\text {-Celina González (1928- } \\
\text { 2015), cantante popular } \\
\text { cubana } \\
\text {-María Malibrán (1808- } \\
\text { 1836), soprano francesa } \\
\text {-Manuel Saumell (1817- } \\
\text { 1870), pianista cubano } \\
\text {-Alejandro García Caturla } \\
\text { (1906-1940), compositor } \\
\text { musical cubano } \\
\text {-Alicia Alonso (1925), } \\
\text { bailarina y coreógrafa } \\
\text { cubana } \\
\text {-Trío Matamoros (1925- } \\
\text { 1960), conjunto musical } \\
\text { cubano de bolero y son } \\
\text { cubano } \\
\text {-Celia Cruz (1925-2003), } \\
\text { cantante cubana } \\
\text {-Sonora Matancera, } \\
\text { agrupación musical cubana }\end{array}$ & $\begin{array}{l}\text {-Ignacio Cervantes } \\
\text { (1847-1905), pianista y } \\
\text { compositor cubano } \\
\text {-El Jilguero de Cienfuegos } \\
\text { (1930-2012), cantante } \\
\text { popular cubano } \\
\text {-Bola de Nieve (Ignacio } \\
\text { Villa Fernández, } \\
\text { 1911-1971), cantante, } \\
\text { compositor y pianista } \\
\text { cubano }\end{array}$ & $\begin{array}{l}\text {-Teresa Stratas (1938), } \\
\text { soprano canadiense } \\
\text {-Renata Tebaldi } \\
\text { (1922-2004), soprano } \\
\text { italiana -María Callas } \\
\text { (1923-1977), soprano } \\
\text { estadounidense } \\
\text {-Ernesto Lecuona } \\
\text { (1895-1963), pianista } \\
\text { y compositor cubano }\end{array}$ \\
\hline
\end{tabular}

Tanto en "El lobo" como en Fresa y chocolate se menciona a los escritores Juan Goytisolo y Mario Vargas Llosa, pero además Diego, ejemplificando su ecléctico gusto, habla del poeta inglés John Donne o de Constantin Cavafis, poeta egipcio en lengua griega y verdadero renovador lírico de las letras helenas, que además comparte condición homosexual con el protagonista. A este respecto, Federico García Lorca aparece citado en el cuento por su viaje a Cuba en 1930 (Paz, 1994: 27), pero en el filme se enumera su nombre junto a autores o personajes históricos y legendarios como Oscar Wilde, Alejandro Magno, Hércules o Aquiles "y dicen las malas lenguas, que hasta Hemingway" apunta Diego. La razón de esa aliteración se debe a que comparten la misma naturaleza que Diego o han mantenido relaciones homosexuales, en esta lista no se añade el nombre de Lezama Lima, al que Diego considera su maestro. De hecho, la novela Paradiso (1966) es como la piedra filosofal de la enseñanza que Diego preconiza en David, desde la imagen de Lezama coronando el altar cubano hasta la recreación y homenaje pantagruélico del almuerzo lezamiano tanto en el filme como en la nouvelle (Paz, 1994: 23). 
Las descripciones homoéroticas que protagoniza José Cemí, personaje principal de la novela, constituido en un álter ego del propio escritor, provocaron que la obra y la vida de Lezama quedase opacada por los aparatos revolucionarios. El escritor vivió en un ostracismo, en el que su discreta condición homosexual no ayudaba, acompañándole este olvido hasta su muerte y perpetuándose en la actualidad la controversia hacia su figura para gran parte de la cultura oficial de Cuba.

En los distintos ámbitos de iniciación, Diego provee a David de referentes que van desde la alta cultura a algunas de las manifestaciones culturales cubanas más populares. Diego es un melómano que escucha preferentemente las interpretaciones de algunas de las mejores sopranos del siglo XX y a compositores clásicos cubanos como Ernesto Lecuona, feroz opositor de la revolución o a Ignacio Cervantes, próximo a los círculos independentistas cubanos, expulsado por este motivo de la isla en 1870 .

Lecuona y Cervantes presentan con Diego analogías vinculadas a su situación de exclusión y marginación (Thibaudeau, 2012), reafirmando varias veces su patriotismo, pues frente al sexo privilegia su sentimiento nacional, "entre una picha y la cubanía, la cubanía" (Paz, 1994: 18). La posición del personaje le hermana con los patriotas independentistas o contrarios a la revolución, desterrados u obligados al exilio por los españoles o por las políticas revolucionarias. La idea del arraigo y la pérdida del mismo, asociada a la capital cubana, aparece en el cine como un lugar de tránsito en la que los oriundos o los migrantes, habaneros de adopción o de estirpe, poseen cierta condición de nómadas, como si ello fuera un rasgo fundamental de los habaneros de nación o de adopción (Sánchez Noriega, 2017). Los temas musicales de Cervantes, "Adiós a Cuba" o "Las ilusiones perdidas" de Cervantes, anticipan la marcha de Diego, el desarraigo del personaje a medida que se acrecienta su exclusión social y se completa su exilio geográfico. Ante lo anterior, Thibaudeau considera que Diego vive un exilio interior, proceso que culmina con su salida final de la isla, empujado por la pérdida del trabajo y la paulatina proscripción que sufre.

En cuanto a la literatura de la isla, en el cuento se subraya la gran importancia que Diego le otorga a la poesía femenina cubana, desde las hermanas Borrero a Dulce María Loynaz. Del mismo modo, señala una serie de escritores imprescindibles para entender la prosa cubana, no sólo acude a Lezama Lima, sino al autor romántico Juan Clemente Zenea ${ }^{11}$. Fresa y chocolate, de forma lógica y funcional, prescinde de referencias que el cuento si asume, como la revista cultural Orígenes (1944-1956) fundada por José Rodríguez Feo (1920-1933) y Lezama. En el texto literario, Diego inicia a David en un campo de estudio que se extiende hacia la antropología o la lingüística, recomendando la lectura de obras tan fundamentales para entender la historia y la idiosincrasia cubana como Azúcar y población en las Antillas (1927) del historiador Ramiro Guerra y Sánchez (1880-1970). sobre la importancia de la industria azucarera en las sociedades caribeñas; Indagación del choteo (1828) del pensador y académico cubano Jorge Mañach y Robato (1898-1961); Americanismos y cubanismos literarios (1932) del político y ensayista cubano Juan Marinello (1898-1977); Contrapunteo cubano del tabaco y el azúcar (1940), obra fundamental del antropólogo cubano Fernando Ortiz (1881-1969), en la que se desarrolla el concepto de transculturación, proceso gradual por el cual una cultura adopta rasgos de otra, hasta culminar en una aculturación y El monte (1954) de la etnóloga Lydia Ca-

11 Fusilado por su condición de independentista por las autoridades coloniales españolas. 
brera (1899-1991), donde detalla los más importantes fundamentos antropológicos, religiosos y culturales del legado afrocubano.

Además de no mencionar lo anterior, es destacable cómo el filme evita dos referentes de la cultura cubana que aparecen en el texto literario: la cantante Celia Cruz y la novela Tres tristes tigres (1965) de Guillermo Cabrera Infante, aunque el nombre de éste ni siquiera se mencione en el "El lobo". Cruz y Cabrera Infante destacaron por su feroz crítica y oposición a la revolución cubana, esta cuestión se aprecia como la demostración evidente de lo siguiente: el film puede criticar aspectos del régimen castrista, pero sin sobrepasar unas determinadas líneas rojas.

\section{Conductas perseguidas, prácticas proscritas: homosexualidad y sincretismo yoruba}

El período especial impone un cambio de prioridades dentro de la nueva realidad sociopolítica cubana y la aparición de alternativas para poder perpetuar la revolución y sobrevivir frente a un sistema capitalista global. Las urgencias del período especial obligan a un cambio de paradigma y las conductas, sexuales o religiosas, aunque no sean integradas por la oficialidad, pasan a ser males menores y caen en una especie de suspenso en las que no se puede negar la realidad, pero tampoco se asume la diversidad.

Esas políticas y prácticas revolucionarias en torno a la homosexualidad se encarnan en el cuento por Bruno, que sería el Miguel del film, caracterizado por ser un "extremista y dogmático que se convierte en el impulso que necesita David (también dogmático, pero mucho más cauto y humano) para tomar el camino equivocado de la persecución y de la delación" (Santana, 1994, 137). Los personajes del cuento, Bruno - como líder de juventudes - e Ismael — como oficial de seguridad del Estado- se yuxtaponen en el personaje de Miguel. Bruno e Ismael funcionan tonalmente como la voz de la conciencia — revolución - para David en "El lobo". Miguel se erige en dogma revolucionario y en guardián de la fe marxista que profesa, en el que su evidente homofobia no le impide intentar perjudicar a su compañero, exigiendo, sin éxito, que Diego firme una carta inculpatoria para que expulsen a David de la universidad. El narcisismo de Miguel también le muestra como un personaje preocupado por cuestiones superficiales como el aspecto físico y rindiendo culto al que parece ser su modelo de masculinidad, James Dean, actor estadounidense e ícono homosexual (Restom, 139: 2003). Esta criptohomosexualidad se reflejaría tanto en los distintos tratamientos del guion de Paz como en el filme, por lo que se puede intuir que la sexualidad de Miguel es notablemente ambigua (Seguin, 2011: 326) y no es todo lo heteronormativa que el pretende transmitir ${ }^{2}$. Aunque la represión hacia los homosexuales no se muestra de forma explícita, está encarnada por las ganas de Miguel - o de Bruno e Ismael - de dar una lección a Diego. Es evidente cómo la diferencia, la forma de pensar o actuar es tomada en su conjunto como conducta peligrosa y tóxica para los intereses revolucionarios. Thibaudeau (2012) señala acertadamente que la homofobia del personaje de Miguel va ligada a la ortodoxia revolucionaria, explicitada de forma atroz en la escena en la que David le pregunta por qué Diego no

12 Las intenciones autorales en el film no evitan esta ambigüedad y en varias escenas se perciben elementos homoeróticos que entran en conflicto con el pensamiento homofóbico y machista por el que se caracteriza Miguel. 
puede ser revolucionario, y Miguel sentencia "porque la revolución no entra por el culo, chico". La frase (Wilkinson, 1999) señala la represión de los elementos críticos de la revolución.

La omisión o el rechazo de grandes literatos cubanos o latinoamericanos por cuestiones de índole ideológica, por su sexualidad o bien por su indiferencia hacia el proceso revolucionario, quedan signadas a lo largo del texto literario y de su traslación fílmica, pero no dejan de resultar atractivas para la sensibilidad de David. Diego, convertido en un sacerdote del conocimiento y la creación artística, constituye una "pléyade de recursos" (Arellano, 2014: 121), en los que, a través de profusas referencias literarias, históricas o musicales, descubre una parte consustancial del repertorio cultural de occidente, insospechado para el aparentemente dogmático David (Tabla 1).

Cuando David lleva fotos del Che y Fidel junto a un brazalete del Movimiento 26 de Julio y los coloca en el altar cubano del apartamento de Diego, comienza un diálogo en el que el estudiante hace una encendida loa a la revolución, justificando que la persecución a homosexuales no es la revolución sino errores de la misma, apostando por un futuro de compresión y aceptación dentro del comunismo cubano frente al escepticismo del propio Diego, descreído de un proceso histórico del que perdió toda fe.

En ese proceso escritural e interpretativo, Diego pasa a ser un personaje cuya condición homosexual se diluye en favor de su posición como cicerone de David. Narrativamente, el desarrollo del personaje de Diego resulta muy artificial y esquemático, el espectador asume la situación porque en ningún momento se atisba representación alguna del amor o las relaciones homosexuales, privilegiándose un modelo de sexualidad heteronormativo, visualizado en el escaparate de una tienda de bodas en la que David ve a dos maniquíes, un hombre y una mujer con trajes nupciales y posteriormente a una pareja vestida al efecto paseando en un auto descapotable. David es quién culmina sus relaciones sexuales - interrumpidas en la pensión con Vivian- con Nancy. Ese binarismo se instituye en la aventura amorosa entre Nancy y David, explicitando que la amistad con Diego no ha remecido la heterosexualidad $\mathrm{u}$ hombría del joven estudiante (Jablonska, 2005: 127). La penúltima escena del filme, en la que desde unas lomas se aprecia una vista general de La Habana, constituye el principio de la despedida de los amigos (Imagen 3). Diego y David hablan del futuro y de la relación de Nancy con el joven estudiante.
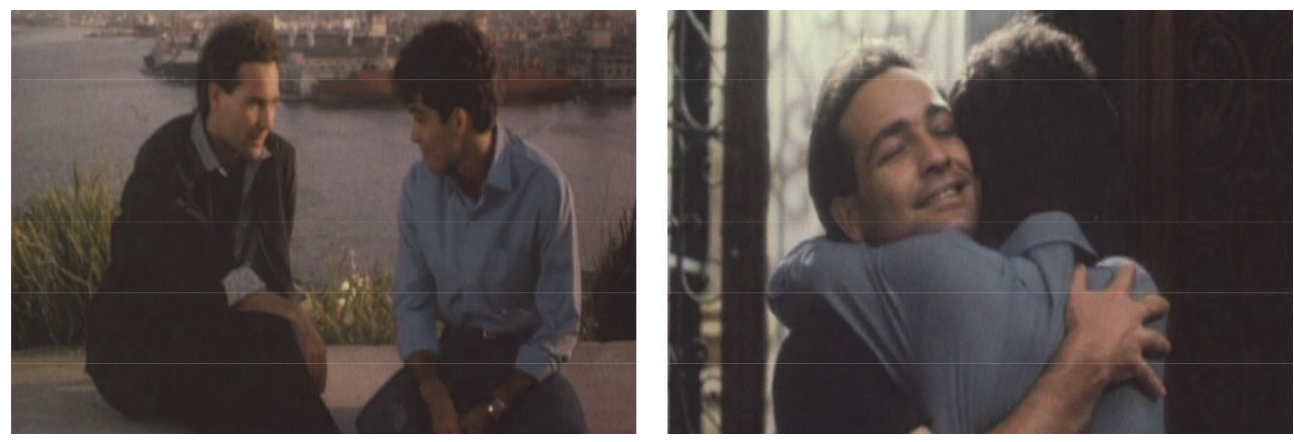

Imágenes 3 y 4. Fragmentos de una despedida y el abrazo final. [Fuente: fotogramas de Fresa y chocolate, Fnac-Avalon (2010)] 
Diego le dice que no le contó cómo se hizo homosexual, "si te lo cuento, sales corriendo", advierte jocosamente el personaje interpretado por Jorge Perugorría. La anécdota de la primera experiencia homosexual de Diego es profusamente descrita en el cuento (Paz, 1994: 12-13). Esa omisión en el filme ahonda y perpetúa el proceso de negación de la realidad homosexual vivida en Cuba.

Cuando se producen las reacciones más desaforadas, que prejuiciosamente, se vinculan a la homosexualidad por parte de Diego, son vistas como una reacción histriónica y en un principio inaceptables para David. En cambio, en la penúltima secuencia, los dos amigos vuelven a la heladería Coppelia y el estudiante imita el primer encuentro de ambos, pastiche que se muestra como una parodia de las maneras femeninas de Diego y reduce su condición homosexual al habla y a las formas de expresión no verbal. A pesar de esta simplificación, al igual que al final del cuento, David reivindica la figura de su amigo en un mensaje de tolerancia y consideración hacia la diversidad ${ }^{13}$. El personaje de Diego no es solamente la encarnación de una forma de disidencia cultural o un estandarte de la diversidad frente a los rigores de la autoridad, al relatar su experiencia de vida describe la crisis de la revolución desde sus mismos cimientos (Deaver: 2013).

El personaje de Nancy resulta esencial para entender algunas de las creencias religiosas de los cubanos. El mismo Diego se declara creyente y simultáneamente en los textos, literario y fílmico, se autorretrata en una declaración de intenciones:

Yo, uno: soy maricón. Dos: soy religioso. Tres: he tenido problemas con el sistema; ellos piensan que no hay lugar para mí en este país, pero de eso, nada; yo nací aquí; soy, antes que todo, patriota y lezamiano, y de aquí no me voy ni aunque me peguen candela por el culo. Cuatro: estuve preso cuando lo de la UMAP (Paz, 1994: 10).

La religiosidad de Diego, educado en un colegio marista (Paz, 1994: 13), resulta muy atemperada en el filme, casi anecdótica, aunque manifiesta su fe al dirigirse a la imagen que tiene de la Virgen de la Caridad del Cobre o derramando whisky en el suelo como ofrenda a los orishas, divinidades yorubas. Pero las creencias de Diego no son tan intensas si se comparan con las de Nancy, devota de la santería. En cambio, el sentimiento religioso del personaje en "El lobo" es recurrente (Paz, 1994: 9, 10, 14, 24). La religiosidad sería uno más de los elementos que manifiestan la "peligrosidad social" de Diego y uno de los aspectos que subraya David cuando le expresa sus sospechas a Miguel, haciendo referencia además a las tallas escultóricas de temática religiosa realizadas por Germán y que Diego quiere exponer con el apoyo de una embajada extranjera.

El sentimiento y la fe religiosas se manifiestan en Nancy, practicante de la santería, que vende productos del mercado negro, lo que no le impide ser la responsable de vigilancia del CDR (Comité de Defensa de la Revolución) de su cuadra y, por tanto, escrutadora de la vida de su vecindad al servicio de las estructuras policiales y del control estatal. Las contradicciones de Nancy son las de la propia realidad cubana, su

13 En la citada aceptación de la diferencia y consolidación de la amistad, el David del cuento resulta más empático en la narración, más sensible que el personaje de Vladimir Cruz, que evoluciona de forma más abrupta en la relación amical con Diego, aunque finalmente el personaje llega al mismo abrazo (Imagen 4), y al mismo convencimiento y respeto en el film. 
devoción a Santa Bárbara (Imagen 5), a la Virgen de la Caridad del Cobre (Imagen 6) y a otros ritos de sincretismo yoruba expresan la normalización social de la santería.
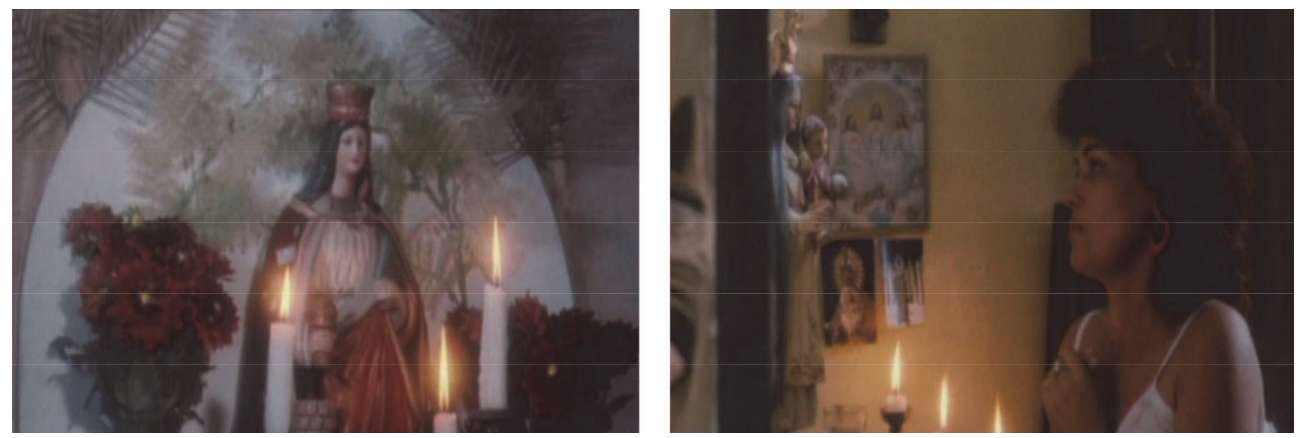

Imágenes 5 y 6. Nancy, devota del sincretismo yoruba cristiano [Fuente: fotogramas de Fresa y chocolate, Fnac-Avalon (2010)]

En palabras de Mirtha Ibarra, la marginalidad que Nancy comparte con Diego tiene mucho de la situación de precariedad de Cuba en el momento del rodaje y el estreno del filme (Mirtha Ibarra, entrevista en Telemadrid - 1995-, recogida en el DVD Fnac-Avalon, 2010). En ese contexto "el sincretismo yoruba-cristiano representa una fuerza integradora capaz de despertar la fe perdida y reestablecer los vínculos rotos por la Revolución" (Sarabia, 2007: 45).

La diversidad religiosa caribeña es parte de la idiosincrasia de los cubanos, aunque su culto se haya llevado en privado, sobre todo en las primeras cuatro décadas de la Cuba comunista. La práctica religiosa es análoga a la homosexualidad, siendo perseguidas con denuedo por parte del aparato represor cubano. La sociedad cubana presenta una especificidad en la que a la gran enorme diversidad étnica habría que añadirle un destacado sincretismo cultural y religioso. Lo anterior se ha estudiado ampliamente en estudios que arrancan de los estudios de Fernando Ortiz (1965) en el campo de la antropología.

\section{Los restos del naufragio: cuando uno sale de Cuba}

La oficialidad cubana y sus estructuras, su marco legal y sus aparatos impregnados de un machismo disfrazado de dogma marxista, no coinciden con algunas de las realidades de la isla. Si se piensa en la homosexualidad o en la práctica de la santería, cuestiones nada periféricas en el filme, se puede afirmar que, a pesar de ser perseguidas por los "guardianes de la revolución", cuentan con una visibilidad que ha ido in crescendo en las últimas décadas. La atenuación por parte del poder del control hacia muchas de estas conductas, reflejan situaciones y modus vivendi que atañen exclusivamente a la vida privada de los cubanos. Parafraseando la obra de Michel Foucault, por mucho que el gobierno cubano haya querido "vigilar y castigar" sexualidades, prácticas o conductas anormativas dentro de los parámetros de la Revolución, la represión de las mismas se ha demostrado inútil y le ha otorgado una posición difícil de sostener o defender. Manifestaciones literarias o fílmicas como 
"El lobo" y Fresa y chocolate ponen de relieve unas condiciones, que, de facto, eran imposibles de controlar para el aparato policial cubano, admitidas y consensuadas por gran parte de la sociedad de la isla. Lejos de normalizar situaciones sociales, el cuento y la película muestran escenas y costumbres cotidianas, a pesar de la omisión de las mismas por parte de la oficialidad.

Uno de los elementos reconocibles a nivel escritural de Senel Paz en su obra es que de forma accesoria y casual proyecta comentarios sobre la situación social y política de Cuba, acentuando lo "desenfadado", glosando características controvertidas de la Revolución (Seguin, 2011: 326). No se puede obviar el contexto de producción, representar el hecho homosexual en un cuento o en un filme en la Cuba revolucionaria, no evita pensar que la simpatía que genera el personaje de Diego se debe a cuestiones que en nada tienen que ver con la aceptación de su naturaleza. Hasta 2007, el film no fue emitido en la televisión cubana. Situación que contrasta con el éxito del que gozó el largometraje en las proyecciones en la isla, tal y como apunta Mirtha Ibarra, viuda de Gutiérrez Alea y protagonista de Fresa y Chocolate, al hablar del estreno en el Festival de Cine Latinoamericano de La Habana de 1993 (2007: 389).

Teniendo en cuenta el historial represor y el discurso homófobo defendido por el gobierno cubano durante décadas, el filme estaba vetado para su difusión catódica al ser considerado como una obra critica. Como apunta Paz, que no fuese emitido en la televisión cubana hasta catorce años después de su estreno se debió a la oposición del oficialismo (Simis, 2015: 83). No obstante, aunque investigadores como Sullivan Charles Barros (2015) han analizado Fresa y chocolate como un ejemplo de cine queer latinoamericano, resulta demasiado tibio si se considera la situación del colectivo LGTBI (Lesbianas, Gais, Transexuales, Bisexuales e Intersexuales) en la isla desde 1959. La legislación y el aparato policial cubanos rechazaron sistemáticamente la homosexualidad, siendo responsables directos de la exclusión y persecución de miles de personas, de internamientos, torturas y crímenes contra la población homosexual. Daba igual la ideología, su naturaleza era disidente con la revolución, obligando al exilio o al confinamiento social de una significativa parte de la sociedad cubana. La pretensión de Diego de alfabetizar y contribuir a la revolución era imposible, pues su condición le excluía para el desempeño de la educación y de ahí su internamiento en una de las "granjas de trabajo" de las UMAP. Para el escritor y exiliado cubano Roger Salas, tanto el cuento de Paz como el film buscan dar carta de naturaleza a la aceptación y tolerancia de la homosexualidad en Cuba, incluso apunta que sería una operación orquestada por el castrismo para atraer el turismo homosexual hacia la isla (Balutet, 2013). Se hace constatable que Cuba ha vivido un período de notables transformaciones desde el éxodo de Mariel y desde el estreno del filme, constatándose en las políticas impulsadas para favorecer la situación del colectivo LGTBI, encarnadas en la figura política de Mariela Castro Espín, hija de Raúl Castro (Negrón-Muntaner, 2008: 164).

Junto a las anteriores valoraciones ideológicas, Fresa y chocolate facilita el estudio del desgaste del proceso revolucionario en Cuba y la asfixia económica provocada por la caída de la Unión Soviética y aislamiento del bloque estadounidense. El período especial abre un momento de miseria y urgencia social de la isla, proyectando la identidad y el imaginario extremo de una situación de carestía absoluta (GarcíaReyes y Ruiz García, 2017). En cambio, el contexto de producción del cuento de Paz, previo al colapso soviético y del filme de Gutiérrez Alea y Tabío, gestado en pleno período especial, se inhiben cronológica y narrativamente de las condiciones 
extremas soportadas por la sociedad cubana. El cuento es incapaz de proyectar la materialidad física de un derrumbe material y moral, pero la cinta expone estéticamente la cruel realidad vivida por los cubanos en este tiempo histórico.

La realidad física de La Habana queda plasmada cuando Diego describe, desde su balcón, la ciudad y por extensión el contexto de la isla: "Vivimos en una de las ciudades más maravillosas del mundo, todavía estás a tiempo de ver algunas cosas. Antes de que se derrumbe y se la trague la mierda". El tono fúnebre hace que David le pida que no sea tan pesimista, pero Diego tiene claro que la inacción de los gobernantes es el motivo de esa decadencia (Imagen 7). En la secuencia posterior, David pasea por La Habana orientado por algunos apuntes de Diego y aprecia edificios históricos, arquitecturas más modernas apuntaladas por andamios, ruinas y escombros (Imagen 8), es sin saberlo ¿la metáfora de un país en demolición?
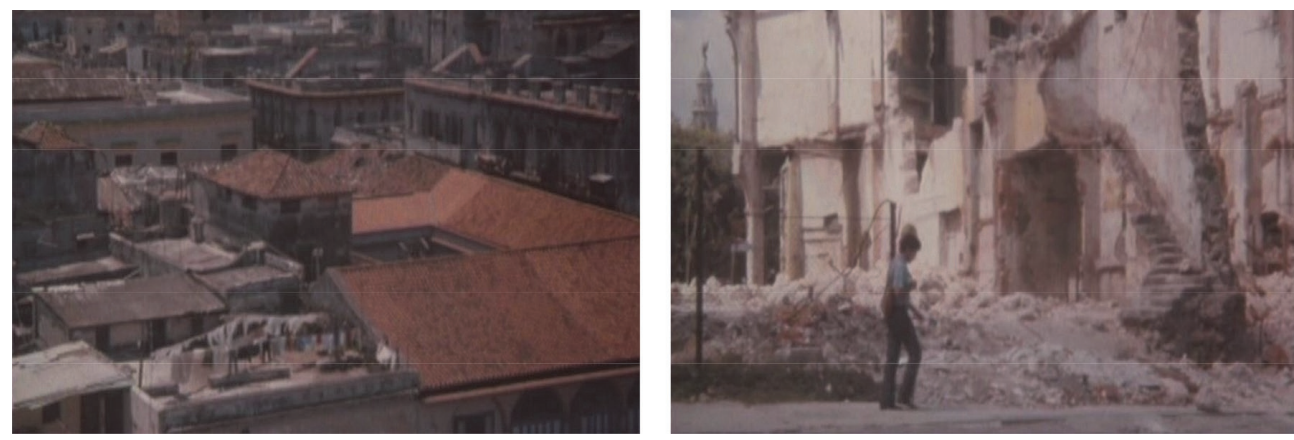

Imágenes 7 y 8 . Azoteas del Centro Habana y David paseando ante las ruinas de un edificio cerca de la Capitanía General de La Habana. [Fuente: fotogramas de Fresa y chocolate,

Fnac-Avalon (2010)]

Por mucho que se quiera contar una historia ambientada a finales de la década del setenta, es imposible disimular las escenografías urbanas de La Habana de finales del siglo XX. La decadencia arquitectónica de la ciudad es un proceso secular y los exteriores del film no son una postal, son el pie de foto del desastre, los restos de un naufragio sin alegorías.

\section{Bibliografía}

Arellano Hernández, Luis Alberto (2014). "Lo lezamiano en la conformación de El lobo, el bosque y el hombre nuevo de Senel Paz”. Valenciana, vol. 7, núm. 14, 117-140.

Balutet, Nicolás (2013). "Las paradojas de Fresa y chocolate (1993), de Tomás Gutiérrez Alea”. Imagofagia, núm. 8. Recuperado de http://asaeca.org (Fecha de acceso: 03/05/2018).

Barros, Sullivan Charles (2015). "Cinema Queer Latinoamericano: diálogos e entrelaçamentos em gênero e (homo) sexualidades por meio dos filmes "Plata Quemada" e "Morango e Chocolate". Revista de Estudos e Pesquisas sobre as Américas, vol. 9, núm. 2. Recuperado de http://periodicos.unb.br/ (Fecha de acceso: 26/04/2018).

Brémard, Bénédicte (2017). "Fresa y chocolate". En José Luis Sánchez Noriega (Ed.). Trayectorias, ciclos y miradas del cine español (1982-1998). Barcelona: Laertes, 341-344. 
Deaver, William O. Jr. (2013) "Fresa y chocolate: A Subtle Critique of the Revolution in Crisis," The Coastal Review: An Online Peer-reviewed Journal, vol. 4, iss. 1, art. 4. Recuperado de https://digitalcommons.georgiasouthern.edu/ (Fecha de acceso: 12/04/2018).

Domínguez Búrdalo, José (2006): "Castradas señas de identidad: Cuba en la obra de Juan Goytisolo". Arizona Journal of Hispanic Cultural Studies, vol. 10, 131-150.

García-Reyes, David y Ruiz García, Sergio (2017). "Identidades urbanas en Trilogía Sucia de La Habana, de Pedro Juan Gutiérrez”. Izquierdas, 37, 212-225.

Gutiérrez Alea, Tomás (1984). “ ¡Cuba Sí, Almendros No!”, The Village Voice, 2 de octubre, Recuperado de http://www.walterlippmann.com/docs1426.html (Fecha de acceso: 08/05/2018).

Gutiérrez Alea, Tomás y Tabío, Juan Carlos (Cuba-España-México, 1993). Fresa y chocolate. Madrid: Fnac-Avalon (2010).

Helg, Aline (1995). Our rightful share: the afro-cuban struggle for equality, 1886-1912. Chapel Hill: The University of North Carolina Press.

Ibarra, Mirtha (Ed.) (2005). Tomás Gutiérrez-Alea, Titón, volver sobre mis pasos. Madrid: Ediciones y Publicaciones Autor.

Jablonska, Alexandra (2005). "Las perspectivas de los narradores en «El lobo, el bosque y el hombre nuevo» de Senel Paz y su adaptación fílmica”. El Cuento en Red, núm. 12, 122-130. Recuperado de http://cuentoenred.xoc.uam.mx/ (Fecha de acceso: 10/05/2018).

Lam, Rafael (2016). "Las cinco décadas de Coppelia, la Catedral del Helado cubano". Granma. Recuperado de http://www.granma.cu/cuba/ (Fecha de acceso: 08/06/2018).

Naranjo, Consuelo y García González, Armando (2000). "Blanqueamiento, "higiene racial" y exclusión en Cuba”. Espace Caraïbe Amériques, núm. 1, pp. 167-182.

Naranjo, Consuelo (2007). "El peso de la esclavitud en Cuba: miedo y recelos contra una población”, en Opratrný, Josef (Ed.). Pensamiento caribeño. Siglos XIX y XX, pp. 313-326Praga: Iberoamericana.

Nascimento, Marcos (2015). "Fresa y Chocolate: los sentidos de la masculinidad en las relaciones de amistad entre hombres homo y heterosexuales". Polifonía Scholarly Journal, vol. V, iss. I, 38-49. Recuperado de http://www.apsu.edu/polifonia/v5/2015-nascimento. pdf (Fecha de acceso: 10/05/2018).

Negrón-Muntaner, Frances (2008). “'Mariconerías' de Estado: Mariela Castro, los homesexuales y la política cubana", Nueva Sociedad, núm. 218, 167-179.

Ortiz, Fernando (1965). La africanía de la música folklórica de Cuba. La Habana: Editora Universitaria.

Paz, Senel (1994). El lobo, el bosque y el hombre nuevo. Sancti Spíritus: Ediciones Luminaria.

Paz, Carlos (1997). "Fresa y chocolate; el lenguaje”. Literatura y lingüística, núm. 10, 67-81. Recuperado de https://dx.doi.org/10.4067/S0716-58111997001000004 (Fecha de acceso:08/05/2018).

Restom Pérez, Marcela Patricia (2003). Hacía una teoría de la adaptación: cinco modelos narrativos latinoamericanos. Tesis doctoral. Universitat Autònoma de BarcelonaDepartament de Filologia Espanyola. Recuperado de Tesis en Red: http://hdl.handle. net/10803/4873, (Fecha de acceso: 16/03/2018).

Sánchez Noriega, José Luis (2017). "La Habana: ciudad de tránsitos, migraciones y exilios". En Camarero Gómez, M. Gloria (Coord.). Ciudades americanas en el cine. Tres Cantos: Akal, 257-278.

Santana, Gilda (1994). "Fresa y chocolate, el largo camino de la literatura al cine”, Viridiana, núm. 7, 131-140. 
Sarabia, Diana (2007). Sueños y desencantos en novelas y películas cubanas del Periodo especial. Tesis presentada en la University of Ottawa (Ontario). Recuperado de: https:// www.ruor.uottawa.ca/ (Fecha de acceso: 4/05/2018).

Seguin, Jean-Claude (2011). "El lobo de fresa y el bosque de chocolate. Senel Paz y sus variaciones cinematográficas", ARBOR Ciencia, Pensamiento y Cultura, vol. 187, núm, $748,325-335$.

Simis, Anita (2015). "Entrevista a Senel Paz: Cinema cubano em transição", Eptic online: revista electronica internacional de economia política da informaçao, da comuniçao e da cultura, vol. 17, n. 3, 73-85, Recuperado de https://seer.ufs.br/index.php/eptic/article/ view/4303/pdf (Fecha de acceso: 23/04/2018).

Thibaudeau, Pascale (2012). "Del chocolate a la fresa, del exilio interior a la expatriación: las etapas de un doble recorrido iniciático en Fresa y chocolate de Tomas Gutiérrez Alea y Juan Carlos Tabío". Les Cahiers ALHIM, núm. 23. Recuperado de https://alhim.revues. org/4246 (Fecha de acceso: 12-03-2018).

West, Dennis (1995). "Strawberry and Chocolate', Ice Cream and Tolerance: Interviews with Tomás Gutiérrez Alea and Juan Carlos Tabío". Cinéaste, vol. 21, núms. 1-2, 16-20.

Wilkinson, Stephen (1999). "Homosexuality and the Repression of Intellectuals in Fresa $y$ chocolate and Máscaras", Bulletin of Latin American Research, vol. 18, iss. 1, 17-33.

Zanetti, Oscar (2013). Historia mínima de Cuba. México: Editorial Turner/El Colegio de México. 